\title{
A non-interventional study of the genetic polymorphisms of NOD2 associated with increased mortality in non-alcoholic liver transplant patients
}

\author{
Fuat Hakan Saner ${ }^{1 *}$, Knut Nowak', Dieter Hoyer ${ }^{1}$, Peter Rath², Ali Canbay ${ }^{3}$, Andreas Paul $^{1}$, Michael Koldehoff ${ }^{4}$ \\ and Ahmet Elmaağaclı ${ }^{4}$
}

\begin{abstract}
Background: Infections after liver transplantation are the main cause of death in the first year. Recent reports indicate that NOD2 gene mutations increase the risk for inflammatory bowl disease and the severity of graft-versus-host disease in bone marrow transplant patients. Data on polymorphisms in liver transplant patients are sparse. We analyzed 13 single-nucleotide polymorphisms (SNPs) of 13 different gene variants including the SNPs of NOD2 genes from liver recipients. The aim of the study was to evaluate the impact of the SNPs on dialysis-dependent kidney failure, the incidence of infections and patient survival.

Methods: During a period of 20-months, 231 patients were recruited in this non-interventional, prospective study. Thirteen different SNPs and their impact on the patients' survival, infection rate, and use of dialysis were assessed.

Results: NOD 2 wildtype genes were protective with respect to the survival of non-alcoholic, cirrhotic transplant patients (3 year survival: $66.8 \%$ wildtype vs. $42.6 \%$ gene mutation, $p=0.026$ ). This effect was not observed in alcoholic transplant recipients.

The incidence of dialysis-dependent kidney failure and infection in the liver transplant patients was not influenced by NOD 2 gene polymorphisms. No effect was noted in the remaining 12 SNPs.

Patients with early allograft dysfunction experienced significantly more infections, required dialysis and had significantly worse survival.

In contrast, the donor-risk-index had no impact on the infection rate, use of dialysis or survival.
\end{abstract}

Conclusion: NOD2 gene variants seem to play a key role in non-alcoholic, liver transplant recipients. However these data should be validated in a larger cohort.

\section{Background}

Immunosuppression, as in liver transplant patients, carries a high risk of life threatening infections such as pneumonia or blood stream infections (BSI). Because calcineurin inhibitors are used as immunosuppressive agents to avoid organ rejection, infections have emerged in the last 20 years as the main cause of death in the first year after transplantation [1,2].

Several risk factors for infections after liver transplantation (LTX) have been identified, such as being male sex, having a prolonged cold ischemia time, acute liver failure,

\footnotetext{
* Correspondence: fuat.saner@uni-due.de

1 Department of General- Visceral- and Transplant Surgery, University

Duisburg-Essen, Hufelandstr 55, 45122 Essen, Germany

Full list of author information is available at the end of the article
}

rejection treatment, relaparotomy due to bleeding or bile, and retransplantation within 30 days [3-5]. Recent reports indicate that single nucleotide polymorphisms (SNPs) are involved in a variety of diseases. Mutations of the toll-like receptor 4 (TLR-4) genes are associated with an increased incidence of inflammatory bowel disease due to bowl alterations such as changes in the bacterial load and translocation [6], whereas TLR-4 mutations in bone-marrow transplant patients are associated with an increased risk for graft-versus-host disease (GvHD) [7]. Nucleotide oligomerisation domain 2 (NOD2) polymorphisms, as a part of the innate immune system, have been shown to be protective against GvHD [7]. Several SNPs in specific genes of liver patients have been evaluated, with conflicting results. Mannose binding lectin (MBL) in the donor was found to carry 
a higher risk for postoperative life threatening infections $[8,9]$. Another clinical study indicates that an MBL gene polymorphism was associated with an increased risk for the development of hepato-cellular carcinoma in chronic hepatitis C patients [10]. The TLR 2 and TLR4-receptors are assumed to recognize hepatitis $\mathrm{C}$ virus. The association between TLR polymorphisms and outcome after transplantation due to chronic hepatitis $\mathrm{C}$ infection was evaluated in a clinical study [11]. The authors found that a homozygous TLR 2 polymorphism was associated with a higher incidence of poor graft function and higher mortality.

NOD2 gene polymorphism is associated with an increased incidence of liver and intestine failure in patients following combined liver and small bowl transplantation [12].

Recently, a group from Rotterdam [13] evaluated 50 polymorphisms in 181 liver transplant patients and their corresponding donors with respect to organ rejection and infections in the recipient. They found no correlation between the gene variants and bacterial and/or fungal infections.

The aim of our study was to evaluate the impact of 13 different SNPs, including in NOD2 and TLR 4, on transplant-associated complications such as infection, need for dialysis and the outcomes of the recipients.

\section{Methods}

During the observation period of $2 / 2009$ to $1 / 2012$, a total of 231 patients were recruited in this prospective, noninterventional study. All patients received liver transplantations at the Medical Center University Essen, Department of General -, Visceral- and Transplant Surgery.

All patients were transplanted with whole liver from a brain-dead donor.

Exclusion criteria were recipient age $\leq 18$ years and lack of a blood sample from the recipient.

This study was conducted in accordance with the amended Declaration of Helsinki. Local institutional review boards of the University Essen approved the protocol, and written informed consent was obtained from all patients.

\section{Surgical procedure and postoperative patient care}

All transplants were accomplished with a liver from a deceased donor. Standardized surgical techniques were used for all recipients as was a strict anesthetic protocol.

A cell saver system was used for all patients who did not have hepatocellular carcinoma. Postoperatively, all patients were treated at a single intensive care unit (ICU) with standardized ICU treatment.

For immunosuppression, the patients received tacrolimus $(0,1 \mathrm{mg} / \mathrm{kg} / \mathrm{d}$ with a targeted plasma level of $5-8 \mathrm{ng} / \mathrm{ml})$, mycophenolatmofetil (1000 $\mathrm{mg}$ twice a day) and intraoperative prednisolone $(10 \mathrm{mg} / \mathrm{kg}$, followed by $40 \mathrm{mg} /$ day), which was gradually tapered within the 6 weeks after liver transplantation. Rejection episodes were treated with intravenous prednisolone (500 mg, 3 times/day).

Intraoperative antibiotic prophylaxis included intravenous ampicillin/sulbactam (3 grams), which was repeated if the operation time was longer than 3 hours. If there were no signs of infection, the antibiotic treatment was stopped after the surgical procedure. Selective digestive decontamination or fungal prophylaxis was not administered to the patients. A preventive treatment with valgancyclovir was performed in almost all patients, but not when both the donor and recipient were CMV IgG negative.

\section{Definitions}

Infections (pneumonia and blood stream infections [BSI]) were diagnosed based on the criteria proposed by the Centers for Disease Control [14], as already described in one of our previously published studies [2]. Briefly, the diagnosis of pneumonia was based on the presence of pulmonary infiltrates together with clinical symptoms suggestive of a lower respiratory tract infection, the identification of a relevant etiologic microbial agent, and the absence of an alternative diagnosis during follow-up. Detection of Aspergillus spp. in the bronchoalveolar lavage was regarded as relevant and was adequately treated.

The diagnosis of BSI was defined as the isolation of gram-positive cocci, gram-negative rods, or any type of fungi in the blood culture.

Sepsis and pneumonia were summarized as clinical significant infections (CSI).

Mortality was defined as death from any cause during the hospital stay or within 1 year after discharge.

Early allograft dysfunction (EAD) was based on the EAD assessment published in 2010 [15]. Briefly, EAD was defined as: Bilirubin $\geq 10 \mathrm{mg} / \mathrm{dL}$ on postoperative day 7 and/or INR $\geq 1.6$ on postoperative day 7 and/or AST or ALT $>2000$ IU/L within the first 7 days.

The donor-risk index (DRI) was assessed as previously described by Feng et al. [16].

\section{Polymorphism genotyping}

DNA was prepared from the PBMCs obtained from the recipient after transplantation using the Magna Pure device from Roche diagnostics (Mannheim Germany). Genotyping for the NOD2/CARD15 gene (SNP8, R702W, rs2066844, SNP12, G908R, rs2066845 and SNP 13, 1007 fs, rs2066847) was performed with a Taqman protocol, as published previously [7,17]. Genotyping for TLR 4 (D299G; rs4986790) and TLR 4 (T399I; rs4987233) was performed and then analyzed using hybridization probes and primers, as previously published [18]. The call rate in a Taqman Genotyper 
Software study for genotyping SNP 8, SNP 12, and SNP 13 was $90 \%$ for each. All tested polymorphisms are listed in Table 1.

The fluorescence-labeled sensor and anchor hybridization probes for the Lightcycler protocol and Taqman probes were purchased from TIB MOLBIOL (Berlin, Germany). Sensor probes cover for the SNPs and exhibit a different temperature depending on binding to the wild type or variant allele. Anchor probes were designed to display a significantly higher melting temperature compared with the corresponding sensor probes. PCR and subsequent melting curve analysis were performed using software for the Lightcycler device. Control samples were included in each run [17].

We included the allele and genotype of the examined SNPs with prefabricated LightSNiP arrays (TIB MOLBIOL GmBH, Berlin, Germany). The 96-well array was company technically with the plate configuration like NOD2, TLR1,-4,-9 and other SNPs compiled. The candidate genotypes were selected mainly based on the literatures that were available on 2009/2010 when the study was initially designed. The allele frequencies are compared with reference population (www.ncbi.nlm.nih.gov and www.hapmap.org) for Caucasian. Genotype probabilities can then be calculated using Hardy-Weinberg equilibrium (HWE) assumption or other assumptions that relate allele frequencies to the allele frequencies.

\section{Statistical analysis}

Continuous data are given as the mean with the standard deviation (SD). Dichotomous or categorical variables are given as numbers with percentage. Differences in continuous variables were calculated using the student's t-test and differences in categorical variables were compared using the Pearson's Chi squared test. KaplanMeier curves were constructed. A p-value $<0.05$ was

Table 1 Polymorphisms (SNPs) tested in all liver transplant patients

\begin{tabular}{ll}
\hline IL 23R & rs11209026 \\
IL 18 RAP & $r s 917997$ \\
TLR1 & $r s 5743611$ \\
TLR4 & $r s 4986790$ \\
TLR9 & $r s 187084$ \\
CARD 9 & $r s 4077515$ \\
NQO & $r s 1800566$ \\
CYP1B1 codon 432 & $r s 1056836$ \\
MTHFR1298 & $r s 1801131$ \\
MTHFR 677 & $r s 180133$ \\
NOD2 G908R & $r s 2066847$ \\
NOD2 L1007F insC & $r s 20666847$ \\
NOD2 R702W & $r s 2066844$ \\
\hline
\end{tabular}

considered statistically significant. Statistical analysis was performed using SPSS statistical software version 20.0 for Mac (SPSS Inc, Chicago III, USA).

\section{Results}

Clinical characteristics and post-transplant clinical significant infections

From $2 / 2009-01 / 2012$, a total of 231 post-liver transplant patients $(67.5 \% \mathrm{~m}, 32.5 \% \mathrm{f})$ were recruited into the study.

The diagnosis leading to liver transplantation were given in Table 2.

The CSI rate was $26.4 \%$, which significantly affected the ventilation time; stay in the ICU; the incidence of dialysis use; and survival rate. The median ventilation time for patients with CSI was $198 \mathrm{~h}(8-3035 \mathrm{~h})$ compared to $20 \mathrm{~h}(0-617)$ in patients without CSI $(\mathrm{p}<$ $0.0001)$. CSI resulted in a median ICU stay of 18 days (2-130), which was significantly longer than the 4 days $(1-27)$ in patients without CSI $(\mathrm{p}<0.0001)$. The incidence of dialysis-dependent kidney failure increased from $26.4 \%$ in patients without infections to $60.6 \%$ in patients with CSI $(\mathrm{p}<0.0001)$. The rate of dialysis in the whole cohort was $32.3 \%$. Table 3 details the clinical and demographic characteristics of both cohorts, patients with and without CSIs.

The 1-year survival rate decreased in patients with CSIs to $42 \%$ compared with $83.7 \%$ in patients without infection $(\mathrm{p}=0.0001)$. The 1-year-survival for all patients was $72.6 \%$.

Table 2 Diagnosis leading to transplantation

\begin{tabular}{ll}
\hline Diagnosis & Number of patients \\
\hline Alcoholic related cirrhosis & 60 \\
Hepatitis C & 63 \\
Hepatitis B & 22 \\
Non-alcoholic-steatohepatitis (NASH) & 15 \\
Acute liver failure & 7 \\
Primary sclerosing cholangitis & 11 \\
Cryptogenic & 12 \\
Polycystic Liver disease & 6 \\
Haemochromatosis & 3 \\
Wilson disease & 5 \\
Autoimmunhepatitis & 6 \\
Hepato-cellular cirrhosis & 3 \\
Secondary sclerosing hepatitis & 7 \\
Primary biliary cirrhosis & 3 \\
Miscellaneous & 8 \\
Total & 231 \\
\hline
\end{tabular}

Miscellaneous: Budd-Chiari Syndome (1); Amyloidosis (2), Cholangiocellular carcinoma (1); Embryonal sarcoma (1); Neuroendocrine tumor (1), secondary biliary cirrhosis (1); alpha 1 antitrypsine deficiency (1). 
Table 3 Clinical variables and characteristics for both cohorts (with and without CSI)

\begin{tabular}{llll}
\hline & $\begin{array}{l}\text { Patients } \\
\text { without CSI }\end{array}$ & $\begin{array}{l}\text { Patients } \\
\text { with CSI }\end{array}$ & P value \\
\hline Age & $52 \pm 9$ & $53 \pm 10$ & 0.8 \\
MELD & $21 \pm 9$ & $25 \pm 11$ & 0.006 \\
Ventilation time (in hours) & $20(0-617)$ & $198(8-3035)$ & $<0.001$ \\
ICU stay (days) & $4(1-27)$ & $18(2-130)$ & $<0.001$ \\
Hospital stay (days) & $21(2-136)$ & $42(3-244)$ & $<0.001$ \\
Incidence of EAD & $18.2 \%$ & $38.7 \%$ & $<0.001$ \\
DRI & $1.8 \pm 0.38$ & $1.7 \pm 0.36$ & 0.16 \\
WIT (min) & $34 \pm 12$ & $33 \pm 7$ & 0.7 \\
CIT (min) & $427 \pm 136$ & $461 \pm 154$ & 0.1 \\
Incidence of Dialysis & $26.4 \%$ & $60.6 \%$ & $<0.001$ \\
\hline
\end{tabular}

CSI: clinical significant infections.

ICU: intensive care unit.

EAD: early allograft dysfunction.

DRI: donor-risk-index.

WIT: warm ischemia time.

CIT: cold ischemia time.

The donor-risk-index (DRI) did not affect either the infection or survival rates. Patients with CSI had a significantly higher lab MELD than patients without CSI ( $25 \pm 10$ vs. $21 \pm 9, \mathrm{p}=0.006)$.

EAD after transplantation affected both the CSI and survival rates. The CSI rate in patients with EAD was $38.7 \%$ compared to $18.2 \%(\mathrm{p}=0.001)$ in patients without EAD. Survival decreased from $78.1 \%$ to $64.7 \%$ $(\mathrm{p}=0.023)$ in patients with severe infection.
Genetic polymorphisms in the non-interventional study group and their impact on infection and survival

The allele and genotype distribution of the SNPs in the different groups (alcoholic and non-alcoholic) were given in the Tables 4 and 5 .

Non-alcoholic patients received a survival benefit from NOD 2 with wild type variants. Non-alcoholic patients with wild type NOD2 genes had a one-year survival rate of $75.4 \%$, whereas the patients with polymorphisms had a survival rate of $49.7 \%(\mathrm{p}=0.026)$ (Figure 1$)$. The difference between wild type NOD2 and polymorphism variants became significant at 6 months after transplantation. This was not the case in alcoholic patients who received liver transplants. The observed 1-year survival in patients with alcoholic disease and a genetic polymorphism for NOD 2 was $83 \%$, which was higher than that in the NOD2 wild type group (64\%), but this did not reach statistical significance. The overall survival for the whole population (alcoholic and non-alcoholic patients) was $72.7 \%$ for the wild type NOD2 vs. $62.5 \%$ for the genetic polymorphism $(p=0.45)$. Table 6 presents the clinical characteristics of the non-alcoholic and alcoholic patients. Patients with non-alcoholic disease were significantly older and required significantly more dialysis treatment.

NOD-2 polymorphism did not affect the incidence of infection $(28.6 \%$ vs. $30.3 \%)$ or incidence of dialysis (33.2\% vs. $30.3 \%$ ). However, NOD 2 polymorphism seems to be protective against EAD. Patients with NOD-2 wild type developed EAD in $44.3 \%$ of the cases, whereas patients with the gene variant had a moderate EAD incidence of $24.2 \%$ $(\mathrm{p}=0.024)$.

Table 4 Characteristics of genes and polymorphisms $\rightarrow$ patients (Pts) with alcoholic liver failure

\begin{tabular}{|c|c|c|c|c|c|c|}
\hline Gene & Allele & rs number & $\begin{array}{l}\text { Wild type genotype } \\
\text { n (\%) }\end{array}$ & $\begin{array}{l}\text { Heterozygote genotype } \\
\text { n (\%) }\end{array}$ & $\begin{array}{l}\text { Homozygote mutation } \\
\mathrm{n}(\%)\end{array}$ & Pts \\
\hline IL23R & $\mathrm{G} / \mathrm{A}$ & 11209026 & $44(85)$ & $8(15)$ & & 52 \\
\hline IL18 RAP & $A / G$ & 917997 & $25(48)$ & $23(44)$ & $4(8)$ & 52 \\
\hline CARD9 & $\mathrm{G} / \mathrm{A}$ & 4077515 & $21(40)$ & $23(44)$ & $8(15)$ & 52 \\
\hline NOD2 & $C / T$ & 2066844 & $40(77)$ & $12(23)$ & & 52 \\
\hline NOD2 & $\mathrm{G} / \mathrm{C}$ & 2066845 & $48(80)$ & $10(17)$ & 2(3) & 60 \\
\hline NOD2 & $-/ C$ & 2066847 & $47(90)$ & $4(8)$ & $1(2)$ & 52 \\
\hline TLR1 & $\mathrm{G} / \mathrm{C}$ & 5743611 & $32(62)$ & $14(27)$ & $6(12)$ & 52 \\
\hline TLR4 299 & $\mathrm{G} / \mathrm{A}$ & 4986790 & $50(96)$ & $1(2)$ & $1(2)$ & 52 \\
\hline TLR4 399 & $\mathrm{G} / \mathrm{A}$ & 4987233 & $48(92)$ & $3(6)$ & $1(2)$ & 52 \\
\hline TLR9 1237 & $C / T$ & 5743836 & $16(31)$ & $27(53)$ & $8(16)$ & 51 \\
\hline TLR9 1486 & $\mathrm{~T} / \mathrm{C}$ & 187084 & $31(61)$ & $19(37)$ & $1(2)$ & 51 \\
\hline NQ01 609 & $C / T$ & 1800566 & 41 (79) & $9(17)$ & $2(4)$ & 52 \\
\hline CYP1B1 432 & $\mathrm{G} / \mathrm{C}$ & 1056836 & $16(31)$ & $20(39)$ & $15(30)$ & 51 \\
\hline MTHFR 677 & $\mathrm{~T} / \mathrm{C}$ & 1801133 & $23(45)$ & $22(43)$ & $6(12)$ & 51 \\
\hline MTHFR 1298 & C/A & 1801131 & $18(41)$ & $23(52)$ & $3(7)$ & 44 \\
\hline
\end{tabular}


Table 5 Characteristics of genes and polymorphisms $\rightarrow$ patients (Pts) with non-alcoholic liver failure

\begin{tabular}{|c|c|c|c|c|c|c|}
\hline Gene & Allele & rs number & $\begin{array}{l}\text { Wild type genotype } \\
\text { n (\%) }\end{array}$ & $\begin{array}{l}\text { Heterozygote genotype } \\
\text { n (\%) }\end{array}$ & $\begin{array}{l}\text { Homozygote mutation } \\
\mathrm{n}(\%)\end{array}$ & Pts \\
\hline IL23R & $\mathrm{G} / \mathrm{A}$ & 11209026 & 138 (93) & $11(7)$ & & 149 \\
\hline IL18 RAP & $A / G$ & 917997 & $75(51)$ & $61(41)$ & $12(8)$ & 148 \\
\hline Card9 & $\mathrm{G} / \mathrm{A}$ & 4077515 & $59(40)$ & $67(45)$ & $22(15)$ & 148 \\
\hline NOD2 & $C / T$ & 2066844 & $128(86)$ & & $21(14)$ & 149 \\
\hline NOD2 & $\mathrm{G} / \mathrm{C}$ & 2066845 & $138(81)$ & $22(13)$ & $11(6)$ & 171 \\
\hline NOD2 & $-/ C$ & 2066847 & $145(97)$ & $3(2)$ & $1(1)$ & 149 \\
\hline TLR1 & $\mathrm{G} / \mathrm{C}$ & 5743611 & $82(55)$ & $56(38)$ & $11(7)$ & 149 \\
\hline TLR4 299 & $\mathrm{G} / \mathrm{A}$ & 4986790 & $128(86)$ & $19(13)$ & $2(1)$ & 149 \\
\hline TLR4 399 & $\mathrm{G} / \mathrm{A}$ & 4987233 & $130(87)$ & $18(12)$ & $1(1)$ & 149 \\
\hline TLR9 1237 & $C / T$ & 5743836 & $50(34)$ & $68(46)$ & $29(20)$ & 147 \\
\hline TLR9 1486 & $\mathrm{~T} / \mathrm{C}$ & 187084 & $90(61)$ & $47(32)$ & $10(7)$ & 147 \\
\hline NQO1 609 & $\mathrm{C} / \mathrm{T}$ & 1800566 & $92(62)$ & $47(31)$ & $10(7)$ & 149 \\
\hline CYP1B1 432 & $\mathrm{G} / \mathrm{C}$ & 1056836 & $59(40)$ & $63(42)$ & $26(18)$ & 148 \\
\hline MTHFR 677 & $\mathrm{~T} / \mathrm{C}$ & 1801133 & $58(39)$ & $66(45)$ & $23(16)$ & 147 \\
\hline MTHFR 1298 & $C / A$ & 1801131 & $67(53)$ & $42(33)$ & $18(14)$ & 127 \\
\hline
\end{tabular}

None of the other SNP gene variants had significant results in the evaluated parameters.

\section{Discussion}

Our study indicates that wild type NOD2 confers a survival benefit to non-alcoholic patients who receive a liver transplant. We recorded a $36 \%$ higher survival in patients with the wild type gene variants compared to the NOD 2 mutation gene variants in this cohort. However, these results were not reproducible for patients with alcoholic disease. In contrast, in patients with alcoholic disease, the gene variant of NOD2 seems to increase survival, though this finding was not statistically significant. Patients with alcoholic disease were significantly older according to statistical analysis, but the difference of 3 years (55 vs. 52 years) seems clinically negligible.

EAD is a serious complication after liver transplantation, which is associated with a higher retransplantation rate and higher mortality [19-21]. EAD was almost 2 times more common in patients with non-alcoholic disease compared to alcoholic patients who received a liver transplant. However, the protective effect of the NOD2 gene with wild type variants overruled the EAD effect.

Recent reports have provided evidence that NOD2 gene variants influence the severity of graft-versus-hostdisease (GVHD) and the transplant survival in bone marrow transplant (BMT) patients.

The Elmaagacli group demonstrated a significantly higher incidence of GVHD in patients with gene variants of NOD2 following BMT compared with patients who had wild type NOD2 [7]. These data are in agreement with a study by Holler et al. [22] in which there was an increased risk of GVHD in patients with an NOD2 gene variant. The authors also reported an increased risk of mortality with the gene variant, which is in contrast with the findings of the Elmaagacli group [7].

The Pittsburgh group evaluated the NOD 2 gene variant in simultaneous liver and small bowel transplanted pediatric patients [12]. They reported that NOD2 gene variants were associated with increased liver and intestinal failure in patients with short-gut syndrome.

Although NOD2, as a part of the innate immune system, plays a key role in preventing bacterial infections, we did not find a difference among patients with and without CSI. Moreover, NOD2 mutations were not associated with a decreased incidence of dialysis use; wild type NOD2 in non-alcoholic patients may have an independent protective effect for survival.

More than a quarter of our patients experienced CSI, which was associated with significantly higher rates of dialysis use, longer ventilation time, length of ICU - and hospital stay, and higher mortality. In an earlier study conducted by our department, the rate of CSI (pneumonia and sepsis) was $32.3 \%$ (24\% sepsis rate and $8.3 \%$ pneumonia rate) [2]. The reason for the higher CSI rate may be related to a different patient population. While only patients with a postmortem organ were recruited in the current study, $24 \%$ of patients in the previous study were transplanted with a graft from a living donor. Biliary complications, including bile leaks, which are associated with sepsis, range from $0.3-22 \%$ in whole organ transplantation $[23,24]$, which is significantly lower than 


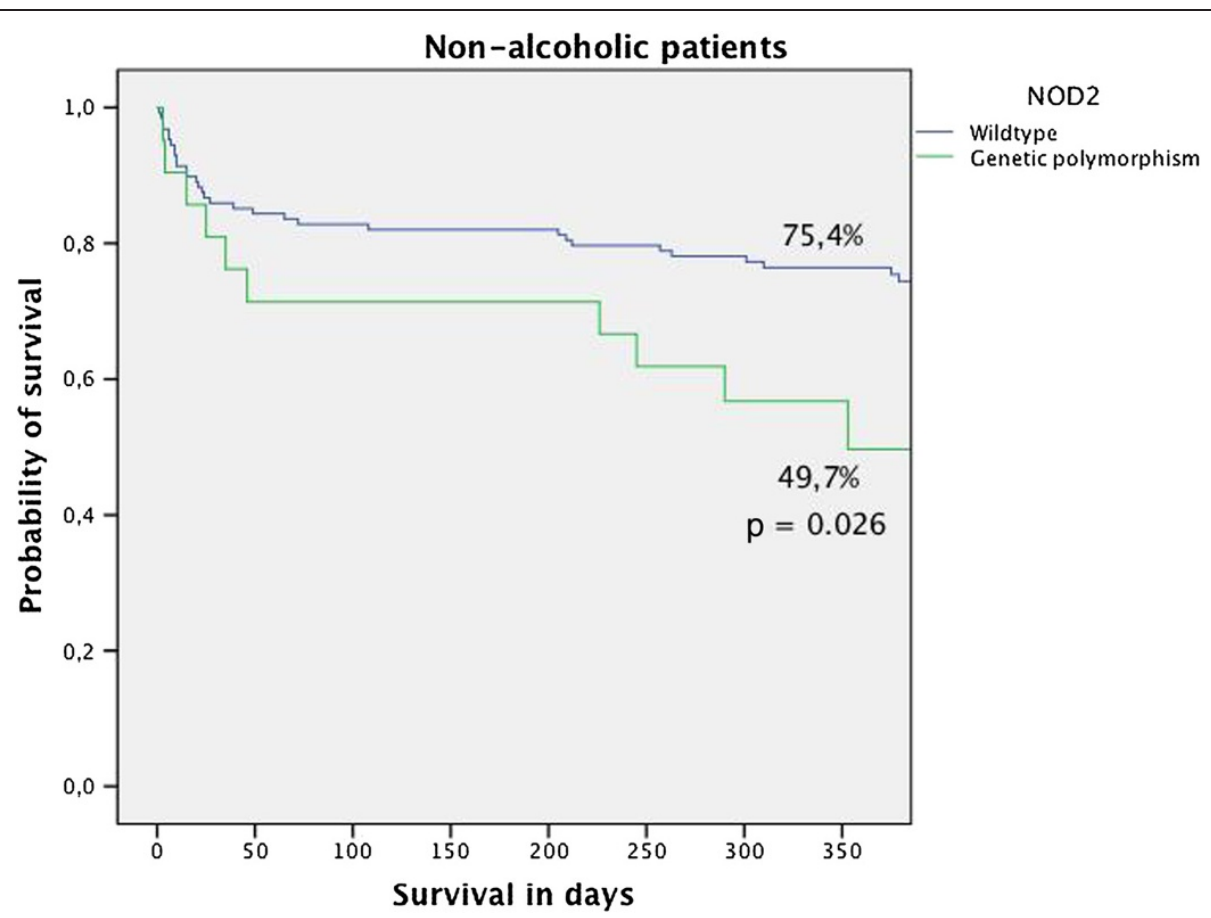

Figure 1 Presents the 1-year survival of patients who received liver transplants for non-alcoholic liver disease. The wild type NOD2 is protective with respect to the survival rate in this cohort. The 1-year survival rate for patients with wild type NOD2 was $75.4 \%$ compared to $49.2 \%$ in patients with the gene variant.

with split liver transplantation with a living donor graft. Some groups reported biliary complications in split liver transplantation of up to $60 \%$ [25], which may contribute to a lower sepsis rate in the current study despite a higher MELD score compared with our own data in the last decade.
A recently published study [26] evaluated the risk factors for infections in 367 patients. The authors reported a CSI (pneumonia and blood stream infection) rate of $28.8 \%$, which is similar to the incidence in our study. In line with this study, Sganga et al. [27] identified a blood stream infection rate of $28 \%$. Unfortunately, neither

Table 6 Clinical variables in alcoholic and non-alcoholic patients

\begin{tabular}{llll}
\hline & Non-alcoholic disease & Alcoholic disease & P value \\
\hline age & $52 \pm 10$ & $55 \pm 8$ & 0.017 \\
CIT (minutes) & $447 \pm 145$ & $406 \pm 124$ & 0.048 \\
WIT (minutes) & $33 \pm 9$ & $34 \pm 15$ & 0.7 \\
MELD & $22 \pm 9$ & $21 \pm 8$ & 0.38 \\
Incidence of EAD & $44.4 \%$ & $28.8 \%$ & 0.024 \\
Incidence of CSI & $25.7 \%$ & $28.3 \%$ & 0.4 \\
Incidence of Dialysis & $35.3 \%$ & $23.7 \%$ & 0.07 \\
DRI & $1.8 \pm 0.4$ & $1.8 \pm 0.3$ & 0.6 \\
Ventilation time (hours) & $35(0-1681)$ & $26(0-3035)$ & 0.2 \\
ICU stay (days) & $5.5(1-71)$ & $5(1-130)$ & 0.4 \\
Hospital stay & $23.5(2-244)$ & $28(3-169)$ & 0.3 \\
\hline
\end{tabular}

ICU: Intensive Care Unit.

EAD: early allograft dysfunction.

DRI: donor-risk-index.

WIT: warm ischemia time.

CIT: cold ischemia time.

CSI: clinical significant infections. 
study reported the survival rate in patients with infection. Our study indicated a nearly $50 \%$ decrease in the one-year-survival for patients who develop a CSI, which is significantly higher than in other groups. Sun et al. [28] evaluated the risk factors for infections in the MELD era. The group stated that the recipient age $(\mathrm{OR}=1.09)$ and the MELD score affect infection. They reported an overall (patients with and without infections) one-year survival rate of $76.7 \%$ in the Pre-MELD era and $82.5 \%$ in the MELD era. In our study, the one-year survival rate was $72.3 \%$ for all patients. The MELD scores in both studies were comparable, but there is a difference of $10 \%$ in the one-year survival of all patients, which may be related to the quality of the donor graft. While in the UNOS region, only $32 \%$ of the transplanted grafts have a DRI of $>1.5$; this rate accounts for $65 \%$ in the EUROTRANSPLANT region. Moreover, only $6 \%$ of the transplanted organs in the UNOS region have a DRI $>2$, but $23 \%$ in the EUROTRANSPLANT area have a DRI $>2$, which is associated with a higher graft failure and lower patient survival [29]. This may in part explain the higher mortality.

There are several studies reporting a worse outcome of liver transplantation in patients with kidney dysfunction and dialysis [30-32]. The registry data of liver transplant patients with postoperative kidney dysfunction demonstrate a significantly worse 2 -year survival compared with patients with adequate or mild kidney dysfunction ( $55 \%$ vs. $76 \%$, $\mathrm{p}<0.05$ ) [33]. These data are in line with a retrospective study that evaluated the risk factors in terms of the survival rate after liver transplantation [34]. Patients with dialysisdependent kidney failure had a one-year survival of less than $50 \%$.

These data are comparable with our study. Sixtysix percent of patients with CSI had dialysisdependent kidney failure, which was associated with a one-year survival $64.7 \%$. Sun et al. reported of a dialysis-dependent kidney failure in less than $10 \%$ of their transplanted patients. In contrast to that study, $32.3 \%$ of our patients required dialysis treatment due to kidney failure, which affects their outcomes. In this context, it is indispensible to highlight the significantly higher dialysis rate in patients with nonalcoholic disease than in alcoholic patients in our cohort. Despite this fact, wild type NOD2 was protective in this patient cohort with respect to their long-term survival.

Our study has some limitations. First, it was a singlecenter study. Because we conducted an observational study, there is no real control group. We did not stratify or evaluate the patients' outcomes with respect to the transplant surgeon or anesthesia team. However because 2007 we have had a constant dedicated surgery and anesthesia team who take care for these patients.

\section{Conclusion}

In conclusion, our data indicates wild type NOD2 offers a survival benefit in liver transplant patients with nonalcoholic disease. Patients with the NOD2 gene variant should have closer follow-up as part of the standard of care. The other SNPs that we tested did not significantly influence the CSI and survival rates in this cohort. Transplantrelated factors may be more dominant risk factors for these patients than the genetic polymorphisms.

\section{Key messages}

1. NOD2 gene polymorphism is associated with higher mortality in patients non-alcoholic disease.

2. DRI has no impact on infection and survivial.

3. EAD is associated with significantly more CSI.

4. Patients with CSI had a significant worse 1-year survival, more common dialysis treatment, longer ventilation time, and longer ICU stay compared to patients without infection.

\section{Abbrevations}

NOD2: Nucleotide-binding oligomerization domain-containing protein 2; SNP: Single nucleotide polymorphism; LTX: Liver transplantation; TLR-4: Toll-like receptor 4; GvHD: Graft-versus-host-disease; ICU: Intensive care unit: IgG: Immunglobulin G; DRI: Donor-risk-index; EAD: Early-allograft-dysfunction; AST: Asparagin transaminase; ALT: Alanine transaminase; ET: Eurotransplant; UNOS: United network for organ sharing; CSI: Clinical signifcant infection; WIT: Warm ischemia time; CIT: Cold ischemia time.

\section{Competing interests}

The authors declare that they have no competing interests.

\section{Authors' contributions}

FS has made substantial contributions to conception and design, acquisition of data and analysis. KN has made substantial contributions to acquisition of data and analysis. DH has made substantial contributions to acquisition of data and analysis. PR had important intellectual contribution for the study design. AP has provided final approval of the version to be published. AC has made substantial contributions to conception, design analysis and interpretation of data. MK has made substantial contributions to conception, design analysis and interpretation of data. All authors read and approved the final manuscript.

\section{Authors' information}

M Koldehoff and A Elmaağaclı contributed equally for senior authorship.

\section{Author details}

'Department of General- Visceral- and Transplant Surgery, University Duisburg-Essen, Hufelandstr 55, 45122 Essen, Germany. ${ }^{2}$ Department of Microbiology, University Duisburg-Essen, 45122 Essen, Germany.

${ }^{3}$ Department of Gastroenterology and Hepatology, University Duisburg-Essen, 45122 Essen, Germany. ${ }^{4}$ Department of Bone Marrow Transplantation, University Duisburg-Essen, 45122 Essen, Germany.

Received: 20 August 2013 Accepted: 30 December 2013

Published: 6 January 2014

\section{References}

1. Blair JE, Kusne S: Bacterial, mycobacterial, and protozoal infections after liver transplantation-part I. Liver Transp/ 2005, 11(12):1452-1459.

2. Saner FH, Olde Damink SW, Pavlakovic G, van den Broek MA, Rath PM, Sotiropoulos GC, Radtke A, Canbay A, Paul A, Nadalin S, et al: Pulmonary and blood stream infections in adult living donor and cadaveric liver transplant patients. Transplantation 2008, 85(11):1564-1568. 
3. Ergin F, Arslan H, Azap A, Demirhan B, Karakayali H, Haberal M: Invasive aspergillosis in solid-organ transplantation: report of eight cases and review of the literature. Transpl Int 2003, 16(4):280-286.

4. Husain S, Alexander BD, Munoz P, Avery RK, Houston S, Pruett T, Jacobs R, Dominguez EA, Tollemar JG, Baumgarten K, et al: Opportunistic mycelial fungal infections in organ transplant recipients: emerging importance of non-aspergillus mycelial fungi. Clin Infect Dis 2003, 37(2):221-229.

5. van den Broek MA, Damink SW, Winkens B, Broelsch CE, Malago M, Paul A, Saner FH: Procalcitonin as a prognostic marker for infectious complications in liver transplant recipients in an intensive care unit. Liver Transp/ 2010, 16(3):402-410.

6. Franchimont D, Vermeire $\mathrm{S}$, El Housni H, Pierik M, Van Steen $K$, Gustot $T$, Quertinmont E, Abramowicz M, Van Gossum A, Deviere J, et al: Deficient host-bacteria interactions in inflammatory bowel disease? the toll-like receptor (TLR)-4 Asp299gly polymorphism is associated with Crohn's disease and ulcerative colitis. Gut 2004, 53(7):987-992

7. Elmaagacli AH, Koldehoff M, Hindahl H, Steckel NK, Trenschel R, Peceny R, Ottinger $\mathrm{H}$, Rath PM, Ross RS, Roggendorf $M$, et al: Mutations in innate immune system NOD2/CARD 15 and TLR-4 (Thr399lle) genes influence the risk for severe acute graft-versus-host disease in patients who underwent an allogeneic transplantation. Transplantation 2006, 81(2):247-254.

8. Bouwman LH, Roos A, Terpstra OT, de Knijff P, van Hoek B, Verspaget HW, Berger SP, Daha MR, Frolich M, van der Slik AR, et al: Mannose binding lectin gene polymorphisms confer a major risk for severe infections after liver transplantation. Gastroenterology 2005, 129(2):408-414.

9. Worthley DL, Johnson DF, Eisen DP, Dean MM, Heatley SL, Tung JP, Scott J Padbury RT, Harley HA, Bardy PG, et al: Donor mannose-binding lectin deficiency increases the likelihood of clinically significant infection after liver transplantation. Clin Infect Dis 2009, 48(4):410-417.

10. Eurich D, Boas-Knoop S, Morawietz L, Neuhaus R, Somasundaram R, Ruehl M, Neumann UP, Neuhaus P, Bahra M, Seehofer D: Association of mannose-binding lectin-2 gene polymorphism with the development of hepatitis C-induced hepatocellular carcinoma. Liver Int 2011, 31(7):1006-1012.

11. Eid AJ, Brown RA, Paya CV, Razonable RR: Association between toll-like receptor polymorphisms and the outcome of liver transplantation for chronic hepatitis C virus. Transplantation 2007, 84(4):511-516.

12. Ningappa M, Higgs BW, Weeks DE, Ashokkumar C, Duerr RH, Sun Q, Soltys KA, Bond GJ, Abu-Elmagd K, Mazariegos GV, et al: NOD2 gene polymorphism rs2066844 associates with need for combined liver-intestine transplantation in children with short-gut syndrome. Am J Gastroenterol 2011, 106(1):157-165.

13. de Mare-Bredemeijer EL, Mancham S, Utomo WK, de C, van Thielen M, de Meester E, Rossau R, van der Laan LJ, Hansen BE, Tilanus HW, et al: Genetic polymorphisms in innate immunity receptors do not predict the risk of bacterial and fungal infections and acute rejection after liver transplantation. Transpl Infect Dis 2012, 15(2):120-133.

14. Garner JS, Jarvis WR, Emori TG, Horan TC, Hughes JM: CDC definitions for nosocomial infections, 1988. Am J Infect Control 1988, 16(3):128-140.

15. Olthoff KM, Kulik L, Samstein B, Kaminski M, Abecassis M, Emond J, Shaked A, Christie JD: Validation of a current definition of early allograft dysfunction in liver transplant recipients and analysis of risk factors. Liver Transp/ 2010, 16(8):943-949.

16. Feng S, Goodrich NP, Bragg-Gresham JL, Dykstra DM, Punch JD, DebRoy MA, Greenstein SM, Merion RM: Characteristics associated with liver graft failure: the concept of a donor risk index. Am J Transplant 2006, 6(4):783-790.

17. Elmaagacli $A H$, Steckel $N$, Ditschkowski $M$, Hegerfeldt $Y$, Ottinger $H$, Trenschel R, Koldehoff M, Beelen DW: Toll-like receptor 9, NOD2 and IL23R gene polymorphisms influenced outcome in AML patients transplanted from HLA-identical sibling donors. Bone Marrow Transplant 2011, 46(5):702-708

18. Elmaagacli $\mathrm{AH}$, Koldehoff M, Beelen DW: Improved outcome of hematopoietic SCT in patients with homozygous gene variant of Toll-like receptor 9. Bone Marrow Transplant 2009, 44(5):295-302.

19. Heise M, Settmacher U, Pfitzmann R, Wunscher U, Muller AR, Jonas S, Neuhaus P: A survival-based scoring-system for initial graft function following orthotopic liver transplantation. Transpl Int 2003, 16(11):794-800.

20. Gonzalez FX, Rimola A, Grande L, Antolin M, Garcia-Valdecasas JC, Fuster J, Lacy AM, Cugat E, Visa J, Rodes J: Predictive factors of early postoperative graft function in human liver transplantation. Hepatology 1994, 20(3):565-573.

21. Deschenes M, Belle SH, Krom RA, Zetterman RK, Lake JR: Early allograft dysfunction after liver transplantation: a definition and predictors of outcome: national institute of diabetes and digestive and kidney diseases liver transplantation database. Transplantation 1998, 66(3):302-310.

22. Holler E, Rogler G, Herfarth H, Brenmoehl J, Wild PJ, Hahn J, Eissner G Scholmerich J, Andreesen R: Both donor and recipient NOD2/CARD15 mutations associate with transplant-related mortality and GvHD following allogeneic stem cell transplantation. Blood 2004, 104(3):889-894.

23. Neuhaus P, Blumhardt G, Bechstein WO, Steffen R, Platz KP, Keck H: Technique and results of biliary reconstruction using side-to-side choledochocholedochostomy in 300 orthotopic liver transplants. Ann Surg 1994, 219(4):426-434.

24. O'Connor TP, Lewis WD, Jenkins RL: Biliary tract complications after liver transplantation. Arch Surg 1995, 130(3):312-317.

25. Corno V, Colledan M, Dezza MC, Guizzetti M, Lucianetti A, Maldini G, Pinelli D, Giovanelli M, Zambelli M, Torre G, et al: Extended right split liver graft for primary transplantation in children and adults. Transpl Int 2006, 19(6):492-499.

26. Avkan-Oguz V, Ozkardesler S, Unek T, Ozbilgin M, Akan M, Firuzan E, Kose H, Astarcioglu I, Karademir S: Risk factors for early bacterial infections in liver transplantation. Transplant Proc 2013, 45(3):993-997.

27. Sganga G, Spanu T, Bianco G, Fiori B, Nure E, Pepe G, D'Inzeo T, Lirosi MC, Frongillo F, Agnes $S$ : Bacterial bloodstream infections in liver transplantation: etiologic agents and antimicrobial susceptibility profiles. Transplant Proc 2012, 44(7):1973-1976.

28. Sun HY, Cacciarelli TV, Singh N: Identifying a targeted population at high risk for infections after liver transplantation in the MELD era. Clin Transplant 2011, 25(3):420-425.

29. Schlitt HJ, Loss M, Scherer MN, Becker T, Jauch KW, Nashan B, Schmidt H, Settmacher $U$, Rogiers $X$, Neuhaus $P$, et al: Current developments in liver transplantation in Germany: MELD-based organ allocation and incentives for transplant centres. Z Gastroenterol 2011, 49(1):30-38.

30. Markmann JF, Markmann JW, Markmann DA, Bacquerizo A, Singer J, Holt CD, Gornbein J, Yersiz H, Morrissey M, Lerner SM, et al: Preoperative factors associated with outcome and their impact on resource use in 1148 consecutive primary liver transplants. Transplantation 2001, 72(6):1113-1122.

31. Brown RS Jr, Lombardero M, Lake JR: Outcome of patients with renal insufficiency undergoing liver or liver-kidney transplantation. Transplantation 1996, 62(12):1788-1793.

32. Gonwa TA, McBride MA, Anderson K, Mai ML, Wadei H, Ahsan N: Continued influence of preoperative renal function on outcome of orthotopic liver transplant (OLTX) in the US: where will MELD lead us? Am J Transplant 2006, 6(11):2651-2659.

33. Nair S, Verma S, Thuluvath PJ: Pretransplant renal function predicts survival in patients undergoing orthotopic liver transplantation. Hepatology 2002, 35(5):1179-1185.

34. Narayanan Menon KV, Nyberg SL, Harmsen WS, DeSouza NF, Rosen CB, Krom RA, Wiesner RH: MELD and other factors associated with survival after liver transplantation. Am J Transplant 2004, 4(5):819-825.

\section{doi:10.1186/1471-230X-14-4}

Cite this article as: Saner et al: A non-interventional study of the genetic polymorphisms of NOD2 associated with increased mortality in nonalcoholic liver transplant patients. BMC Gastroenterology 2014 14:4. 